\title{
Analisis Keterlambatan pada Proyek PT. Jatim Taman Steel di Gresik dengan Menggunakan Lean Six Sigma Framework
}

\author{
Dewa Sang Nyata ${ }^{1, *}$, I Putu Artama Wiguna ${ }^{1}$ \\ Departemen Teknik Sipil, ITS, Surabaya ${ }^{1}$ \\ Koresponden*, Email: hoyadewa@gmail.com
}

\begin{tabular}{ll}
\hline \multicolumn{1}{c}{ Info Artikel } & Abstract \\
\hline Diajukan 27 Juli 2017 & Based on the results of the preliminary survey, there was a two-month delay of completion \\
Diperbaiki 5 Desember 2017 & at PT. Jatim Taman Steel project located in Gresik which was caused by several factors in \\
Disetujui 28 Pebruari 2018 & delays in various construction projects but most of them only use one point of view and there \\
are also some studies which examine how to minimize them. This study is aimed to obtain & the dominant factors causing delay at PT. Jatim Taman Steel projects from three points of \\
view namely the owner, contractor and consultant. The researcher also used the formulation & of solution to overcome the delay by using the approach of Lean Six Sigma concept. Lean \\
Six Sigma has the concept of phase in eliminating waste referring to the waste of time which \\
can be done more efficiently and systematically. The research variables were formulated \\
based on the results of a literature study with measurements using a scale of relevance \\
through questionnaires. Purposive sampling technique was used to conduct sampling. The \\
research respondents are made up of the project managers, expert staffs, directors and \\
engine consultants. The description of variables to the formulation of solution was \\
conducted gradually by using DMAIC phase (Define, Measure, Analyze, Improve and \\
Control) as well as the concept of Lean Construction. As a solution to minimize delays in \\
the construction project of the steel factory at PT. Jatim Taman Steel, the following \\
techniques are used: Alliance \& Partnering, Work Structuring and Daily Huddle Meeting. \\
With these techniques used simultaneously, they can reduce waste of time from 60 days to \\
only about 46 days or able to minimize the delay up to 23.333\%.
\end{tabular}

Abstrak

Proyek PT. Jatim Taman Steel di Gresik mengalami keterlambatan selama dua bulan dalam penyelesaian yang disebabkan oleh beberapa faktor di tahap pra konstruksi dan konstruksi. Penelitian ini bertujuan untuk memperoleh faktor-faktor dominan penyebab timbulnya keterlambatan pada proyek dari tiga sudut pandang yaitu owner, kontraktor dan konsultan, serta perumusannya menggunakan pendekatan Lean Six Sigma Framework. Variabel penelitian dirumuskan berdasarkan hasil studi literatur dengan menggunakan skala relevansi melalui bantuan kuisioner. Untuk pengambilan sampel dengan teknik purposive sampling. Responden penelitian adalah manajer proyek, staf ahli, direktur dan konsultan mesin. Pendeskripsian variabel hingga perumusan solusi dilakukan secara bertahap menggunakan fase DMAIC (Define, Measure, Analyze, Improve dan Control) dimana digunakan konsep Lean Construction di tahap Improve. Untuk meminimalisir keterlambatan pada proyek menggunakan beberapa teknik, yaitu Alliance \& Partnering, Work Structuring dan Daily Huddle Meeting. Sehingga mampu

Kata kunci: Keterlambatan Proyek, menghemat waktu dari 60 hari menjadi \pm 46 hari atau meminimalisir keterlambatan

Lean Six Sigma Framework, DMAIC sebesar $23,333 \%$.

\section{Pendahuluan}

Pada umumnya setiap proyek konstruksi mempunyai perencanaan dan jadwal pelaksanaan tertentu yang bertujuan untuk mengatur pengalokasian sumber daya bersifat terbatas yang mana salah satu dari sumber daya tersebut adalah waktu. Secara garis besar perencanaan terhadap waktu pada proyek konstruksi tertuang dalam bentuk kurva "S" yang secara garis besar menjelaskan kapan proyek akan dimulai hingga kapan proyek harus diselesaikan dengan dikaitkan dengan jumlah item kegiatan, dengan tujuan agar disaat memasuki tahap konstruksi setiap item kegiatan dapat berjalan dengan efisien. Akan tetapi dalam prakteknya tidaklah mudah, sering muncul ketidaksesuaian antara jadwal yang telah dibuat dengan kenyataan yang sebenarnya yang disebabkan oleh berbagai faktor, dampaknya adalah 
keterlambatan penyelesaian proyek yang secara tidak langsung menyebabkan pembengkakan biaya.

Menurut Sambasivan dan Soon, dari hasil penelitian pada beberapa proyek konstruksi di Saudi Arabia hanya $30 \%$ proyek yang dapat selesai tepat waktu sedangkan sisanya mengalami keterlambatan [1]. Berdasarkan hasil investigasi oleh Ernst dan Young, dari total 559 proyek infrastruktur di Negara India, 293 diantaranya mengalami keterlambatan dengan rincian 69 proyek terlambat 1-12 bulan, 67 proyek terlambat 13-24 bulan, 107 proyek terlambat 25-60 bulan dan 37 proyek terlambat lebih dari 60 bulan, yang keseluruhannya menyebabkan penambahan biaya sebesar USD 105 juta [2].

Selain berdampak pada pembengkakan biaya, keterlambatan juga memberikan dampak lainnya. Menurut Messah dkk, keterlambatan dalam proyek konstruksi dapat menyebabkan berbagai bentuk kerugian bagi penyedia jasa maupun pengguna jasa [3]. Bagi penyedia jasa, adanya keterlambatan mengakibatkan menurunkan kredibilitas penyedia jasa untuk waktu mendatang. Sementara bagi pengguna jasa, keterlambatan berpotensi menyebabkan timbulnya perselisihan dan klaim antara peyedia jasa dengan pengguna jasa. Sedangkan yang menyebabkan keterlambatan pada proyek kontruksi antara lain ketidaktepatan perencanaan kerja, identifikasi durasi dan rencana kerja yang tidak lengkap dan tidak tersusun dengan baik, kualitas tenaga kerja yang buruk, metode konstruksi yang salah, perubahan lingkup pekerjaan dan lain-lain. Jika mempertimbangkan bahwa dampak buruk yang disebabkan oleh keterlambatan cukup banyak, maka usaha-usaha untuk menguranginya sangat diperlukan, namun pencapaian tujuan ini tidak akan berhasil dengan baik apabila usaha-usaha tersebut dilakukan secara sporadis tanpa mengetahui dahulu variabel-variabel dominan penyebab keterlambatan.

Penelitian ini merupakan studi kasus yang bertempat di Gresik dengan nama Poyek Jatim Taman Steel 2 dengan main kontraktor PT. Waringin Megah. Proyek ini adalah bagian pengembangan perusahaan agar dapat bersaing dengan perusahaan produksi baja di level Asia Tenggara khususnya bagian proses Rolling Mill.

Rumusan masalah dalam penelitian ini yaitu: 1) faktorfaktor apa sajakah yang menjadi penyebab keterlambatan proyek PT. Jatim Taman Steel di Gresik?, 2) bagaimana mengatasi proses keterlambatan pada proyek PT. Jatim Taman Steel di Gresik dengan menggunakan pendekatan Lean Six Sigma dengan framework DMAIC.

Adapun tujuan dalam penelitian ini yaitu: 1) untuk mengetahui faktor-faktor dominan keterlambatan di proyek PT. Jatim Taman Steel di Gresik, 2) untuk memberikan improvisasi faktor dominan keterlambatan dengan pendekatan Lean Six Sigma Framework dengan studi kasus proyek PT. Jatim Taman Steel di Gresik.

\section{Metode}

Penelitian ini menggunakan metode penelitian kualitatif dengan menggunakan hasil survei responden yang selanjutnya dianalisis menggunakan teknik analisis statistik. Penelitian deskriptif ini meliputi penilaian sikap atau pendapat terhadap individu, organisasi, keadaan atau prosedur yang memberikan gambaran atas suatu keadaan secara menyeluruh dan teliti, yaitu mengenai faktor-faktor yang menjadi penyebab keterlambatan proyek PT. Jatim Taman Steel di Gresik dan penggunaan pendekatan Konsep Lean Six Sigma dengan Lean Construction dalam mengatasi keterlambatan pada proyek JTS di Gresik. Variabel yang digunakan dalam penelitian ini adalah faktor keterlambatan proyek yang diukur dari tiga jenis penyebab keterlambatan proyek, yaitu keterlambatan yang tidak dapat dimaafkan (non excusable delays), keterlambatan yang dapat dimaafkan (excusable delays), dan keterlambatan yang layak mendapatkan ganti rugi (compensable delays).

Adapun untuk mengetahui pendekatan konsep dalam mengatasi keterlambatan pada proyek JTS di Gresik dengan Lean Six Sigma akan diukur menggunakan DMAIC.

Pada fase Define dilakukan identifikasi variabel penyebab keterlambatan, fase ini bertujuan untuk memperoleh variabel-variabel penyebab keterlambatan yang terjadi pada obyek penelitian. Tool yang digunakan adalah kuisioner dengan variabel-variabel dasar diperoleh dari studi literatur penelitian-penelitian terdahulu mengenai faktor -faktor penyebab keterlambatan. Pada fase measure dilakukan pengukuran tingkat pengaruh dari tiap variabel terhadap keterlambatan menggunakan skala likert, tingkat signifikan variabel diukur dengan dasar satuan waktu, artinya jika suatu variabel misalkan variabel $\mathrm{A}$, menyebabkan keterlambatan yang memakan waktu lebih lama dibandingkan dengan variabel $\mathrm{B}$, maka variabel A memiliki tingkat signifikansi yang lebih besar terhadap keterlambatan sehingga variabel A mendapat peringkat lebih tinggi dibandingkan dengan variabel B. Tool yang digunakan adalah kuisioner dengan dasar penilaian menggunakan expert judgement. Pada fase Analyze dilakukan penggalian lebih jauh terhadap variabelvariabel yang memiliki tingkat signifikansi besar yang diperoleh pada fase sebelumnya, untuk itu digunakan teknik wawancara yang secara garis besar menggali bagaimana mekanisme suatu variabel dapat menyebabkan keterlambatan serta bagaimana keterkaitan variabel tersebut ke tiap itemitem kegiatan pada obyek penelitian yang dipengaruhinya, 
hasilnya berupa Current State Mapping. Pada fase Improve akan dibentuk Future State Mapping yang berupa Value Stream Mapping sebagai bentuk perbaikan dari Current State Mapping dengan menerapkan konsep Lean Construction agar menjadi penbeda untuk penelitian sebelumnya dan sebagai inovasi konstruksi di Indonesia untuk perbaikannya. Pada fase Control dilakukan simulasi terhadap Future State Mapping apakah dapat mengatasi keterlambatan secara efisien dengan bantuan program Microsoft Project.

\section{Hasil dan Pembahasan}

Untuk mengetahui pendekatan konsep dalam mengatasi keterlambatan pada proyek JTS di Gresik dengan Lean Six Sigma akan diukur menggunakan DMAIC. Define: dilakukan identifikasi variabel penyebab keterlambatan, fase ini bertujuan untuk memperoleh variabel - variabel penyebab keterlambatan yang terjadi pada obyek penelitian. Tool yang digunakan adalah kuisioner dengan variabel - variabel dasar diperoleh dari studi literatur penelitian - penelitian terdahulu mengenai faktor - faktor penyebab keterlambatan. Measure: dilakukan pengukuran tingkat pengaruh dari tiap variabel terhadap keterlambatan menggunakan skala likert.

Berdasarkan hasil pada tahap Measure didapatkan 3 variabel yang paling dominan yakni Variabel Tanah Longsor (X8), Variation In Quantities (X4) dan Variabel Kesalahan Desain (X5) kemudian dilakukan penggalian informasi lebih lanjut untuk membuat flowchart Current State Mapping fungsinya adalah untuk mengetahui dimana letak kesalahan dan agar perbaikan yang akan dilakukan kedepan bisa terealisasikan dengan mudah karena sudah mengetahui alur yang akan dilakukan perbaikan.

\section{a. Variabel Kesalahan Desain (X5)}

Kesalahan desain atau lebih tepatnya tidak akuratnya desain mengakibatkan biaya dan waktu proyek menjadi terlambat menempati peringkat pertama dari 3 besar penyebab proyek PT Jatim Taman Steel mengalami keterlambatan dengan tingkat signifikansi sebesar $80 \%$ berdasarkan hasil kuisioner. Kesalahan desain terjadi karena perencanaan awal atas pemenuhan kebutuhan owner tidak terpenuhi. Kesalahan pada desain berdampak fatal dalam proses pelaksanaan, terlihat pada Gambar 1 yang berdampak pada kinerja, biaya dan mutu. Desain merupakan pencerminan dari kebutuhan owner, sehingga di awal perencanaan desain harus benar-benar mengidentifikasi semua kebutuhan owner secara detail dan bisa meminimalisir pekerjaan ulang.

\section{b. Variabel Variation in Quantities (X4)}

Variation in quantities atau lebih tepatnya perbedaan volume pekerjaan dengan estimasi awal proyek menempati peringkat kedua dari 3 besar penyebab proyek PT. Jatim Taman Steel mengalami keterlambatan dengan tingkat signifikansi sebesar $80 \%$. Banyaknya perubahan dalam desain yang tertuang pada change order menyebabkan penyelesaian proyek PT. Jatim Taman Steel menjadi terlambat dari jadwal rencana, selain karena permintaan owner yang berubah - ubah, perubahan desain terjadi akibat perubahan spesifikasi serta dimensi mesin yang akan ditempatkan pada pabrik tersebut dari spesifikasi mesin awal, sehingga diperlukan adanya desain baru untuk mengakomodasinya. Adanya perubahan galian, pembesian dan anchor memerlukan waktu untuk merencanakan dan pembuatannya kembali. Untuk visualisasi pembesian dan anchor yang telah mengalami perubahan desain ada pada Gambar 2 dan Gambar 3.

\section{c. Variabel Variation in Quantities (X4)}

Tanah Longsor menempati peringkat ketiga dari 3 besar penyebab proyek PT. Jatim Taman Steel mengalami keterlambatan dengan tingkat signifikansi sebesar $80 \%$, tanah longsor menyebabkan 2 set kolom pedestal roboh serta 6 tiang pancang yang telah tertanam patah (gambar 4).

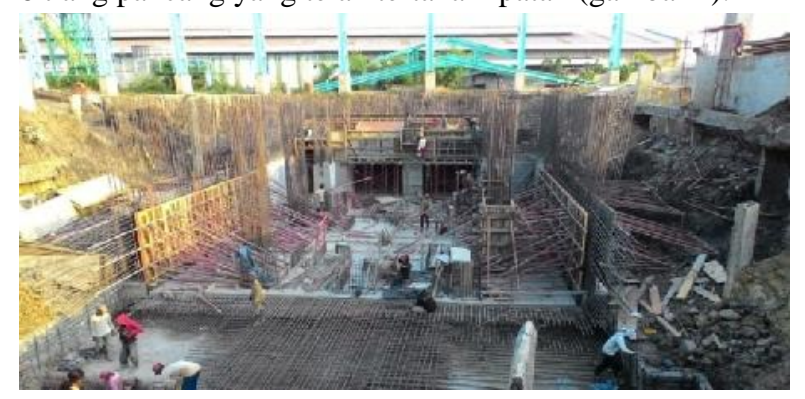

Gambar 1. Galian untuk Pondasi Mesin dan Kolom Terlalu Dekat

Sumber: Hasil Analisa

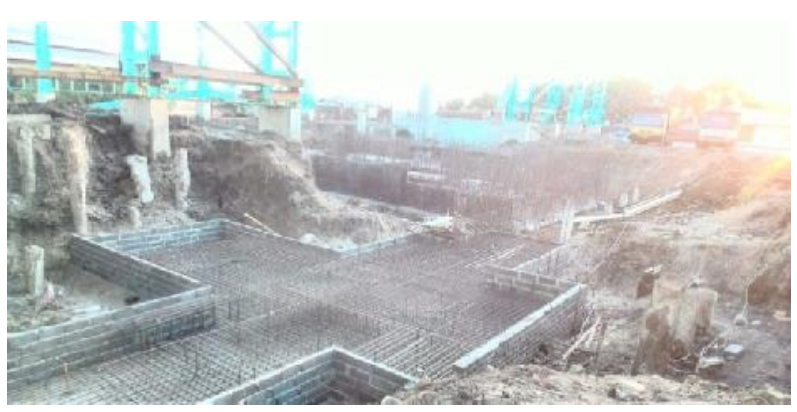

Gambar 2. Pembesian Mesin yang Telah Mengalami Perubahan Desain

Sumber: Hasil Analisa 


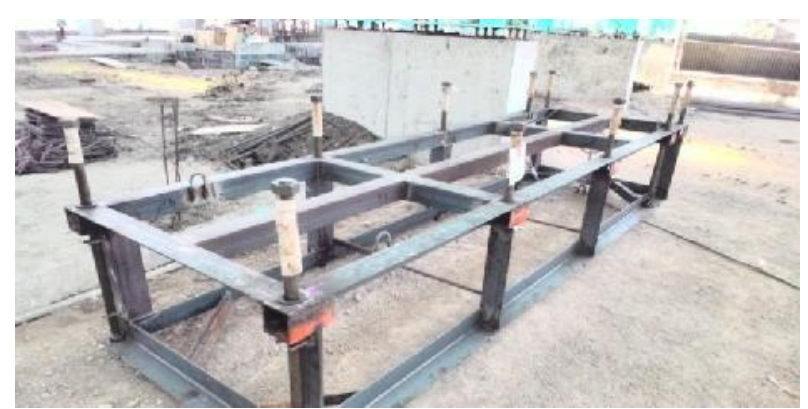

Gambar 3. Pembuatan Anchor yang Telah Mengalami Perubahan Desain

Sumber: Hasil Analisa

Hal ini disebabkan oleh durasi turunnya hujan yang lama dengan kriteria hujan lebat ditambah dengan lokasi kolom pedestal terletak dekat dengan galian pondasi mesin tanpa diberikan penahan.

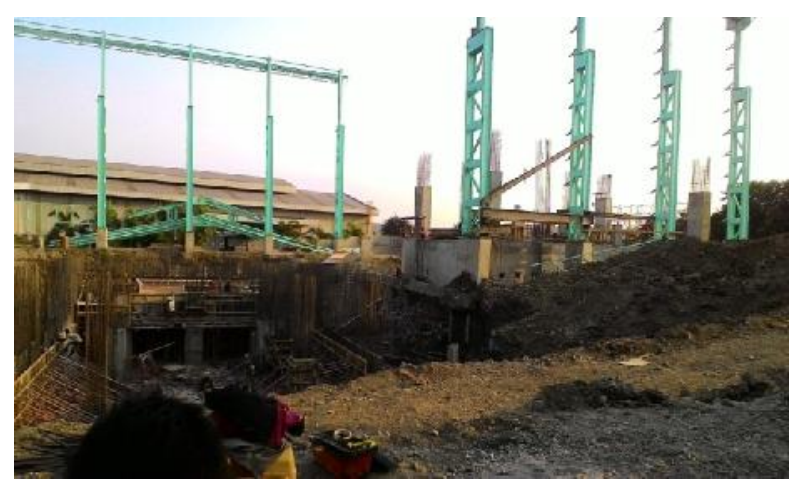

Gambar 4. Lokasi Longsor di PT Jatim Taman Steel Sumber: Hasil Analisa

\section{d. Improve Tanah Longsor}

Yang bisa diterapkan sebagai improve sesuai konsep Lean Construction:

1) Memberikan perkuatan tanah dengan menambahkan Sheet Pile di galian pondasi.

2) Melalukan upaya preventif dengan cara mengecek apakah terdapat retakan pada tanah, jika ditemukan maka segera tutup celah retakan itu dengan tanah lempung supaya tidak banyak air masuk kedalam celah retakan tersebut.

3) Mengecek kondisi muka air tanah dan surcharge load yang bekerja di sekitar galian untuk mengantisipasi longsoran.

4) Penerapan lean construction dalam mencegah longsor adalah kontrol terhadap ketepatan metode pelaksanaan termasuk penerapan K3, sehingga lebih sedikit terjadi kecelakaan.

\section{e. Proses Improve Tanah Longsor}

Proses improve tanah longsor seperti terlihat pada gambar 5.

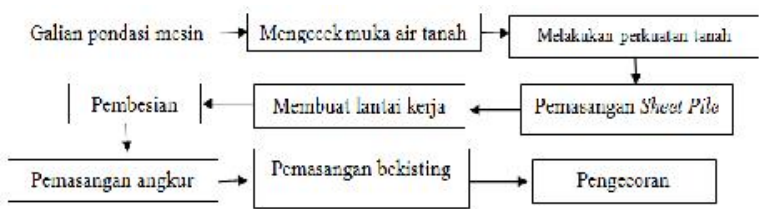

Gambar 5. Flow Improve Future State Mapping Tanah Longsor

\section{f. Value Stream Mapping Tanah Longsor}

Untuk mencegah timbulnya longsor di tahap improve maka perlu ditambahkan pekerjaan pemasangan sheet pile di sekeliling galian yang memakan waktu selama 15 hari dan perlu dilakukan pengecekan kondisi tanah untuk lebih memastikan selama 8 hari dengan mengorbankan waktu selama 23 hari mampu mengurangi keterlambatan selama 38 hari atau sekitar $15 \%$ dari total waktu penyelesaian proyek actual (gambar 6).

\section{g. Control}

Fase control merupakan fase untuk memantau agar alternatif perbaikan yang telah direncanakan dapat benarbenar diaplikasikan. Mekanisme control yang pertama adalah pembuatan control sheet untuk mengingatkan kontraktor mengenai hal-hal yang harus mereka lakukan sebagai total productive maintenance. Selain itu kedepannya diperlukan control chart secara berkala untuk mengetahui proses in control atau tidak.

Data dan informasi seperti desain dan gambar kerja, dipelajari dan dievaluasi kemudian dibuat lebih detail dan cermat dalam bentuk gambar teknis di lapangan. Gambar teknis di lapangan nantinya dimintakan kepada pemilik proyek dan konsultan perencana untuk disetujui dan dijadikan gambar pelaksanaan.

Dengan acuan jadwal rencana yang dikeluarkan oleh pemilik proyek, dilakukan penyesuaian jadwal yang logis berdasarkan kegiatan-kegiatan proyek yang ada serta identifikasi hambatan dan peluang terhadap penyelesaian proyek sesuai dengan rencana. Jadwal rencana proyek harian, mingguan dan bulanan. Agar memudahkan pada saat controling kembali pada saat proyek sudah jauh berlangsung.

Penggunaan sumber daya merupakan termasuk hal penting dalam pelaksanaan dan pengendalian proyek, karena berhubungan langsung biaya dan penggunaannya agar diperoleh penggunaan sumber daya yang optimal, sehingga perlu dibuatkan jadwal tersendiri dan komitmen untuk selesai dengan tepat sesuai dengan konsep Lean Construction yakni 
komitmen agar proyek berjalan dengan semestinya dan berjalan sesuai dengan konsep awal.

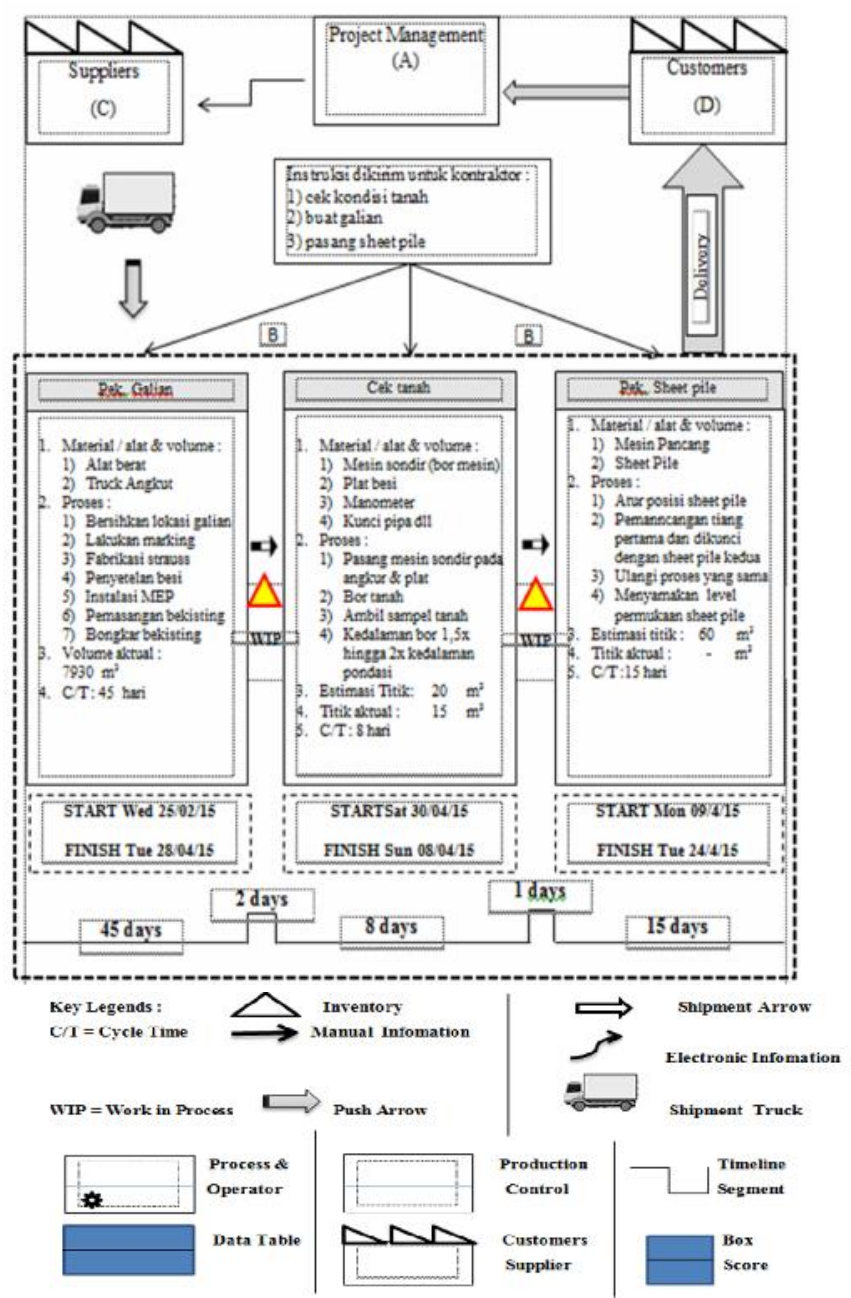

Gambar 6. Value Stream Mapping Tanah Longsor

Bentuk untuk pelaporan proyek diusahakan dengan prinsip-prinsip, mudah dibaca, mudah diperbarui dan sederhana. Usahakan ada pemisah terhadap laporan-laporan karena ada perhatian khusus terhadap master schedule, sub schedule, peralatan dan tenaga kerja proyek. Berikut rincian hasil tahap improve yang akan disajikan pada Tabel 1.

Pada tabel 1 dapat dilihat bahwa dengan melakukan improve menggunakan teknik Lean Construction terhadap 3 variabel signifikan sebagai variabel penyebab keterlambatan pada proyek pabrik baja khusus JTS 2 mampu mengurangi waktu keterlambatan sebesar 24,667 \% jika dirata-rata keseluruhannya dan proses pengolahan di Microsoft Project. Pada tahapan define sebelum mencari faktor yang dominan, terlebih dulu mencari nilai relevan dan tidak relevan yang didapatkan dari studi literatur sebanyak 41 variabel penyebab keterlambatan pada proyek konstruksi. Hasil dari studi literatur tersebut digunakan dalam kuisioner yang menghasilkan 18 variabel relevan penyebab keterlambatan pada proyek dengan menggunakan responden Direksi, Project Manager dan Staff. Populasi pada studi ini yaitu pihak owner, konsultan dan kontraktor. Untuk memperoleh variabel yang signifikan maka digunakan bantuan kuisioner kembali dengan menggunakan skala penilaian Likert.

Dari hasil kuisioner utama ini diambil 3 variabel yang paling signifikan untuk dilakukan analisa lebih lanjut dengan tujuan mengurangi keterlambatan yang terjadi dengan melakukan improve pada tiga variabel tersebut dengan konsep Lean Construction. Berdasarkan hasil analisa terhadap kuisioner utama, 3 variabel tersebut adalah Tanah Longsor (80\%), Variation in Quantities (82\%) dan Kesalahan Desain (87,5\%). Pada variabel pertama yaitu Variation In Quantities, digunakan konsep Lean Construction yang dapat diaplikasikan teknik Alliance \& Partnering. Menurut Abduh, owner tidak menggunakan 1 konsultan mesin tetapi berpartner dengan lebih dari 1 konsultan mesin sehingga apabila 1 konsultan mesin tidak dapat menyediakan spesifikasi mesin yang dipersyaratkan, owner masih dapat memperoleh mesin sesuai persyaratan dari konsultan mesin lainnya [4].

Tabel 1. Hasil Improve Menggunakan Teknik Lean Construction

\begin{tabular}{ccccccc}
\hline No. & Tahapan & $\begin{array}{c}\text { Variabel Penyebab } \\
\text { Keterlambatan }\end{array}$ & $\begin{array}{c}\text { Waktu Aktual } \\
\text { (hari) }\end{array}$ & $\begin{array}{c}\text { Waktu Setelah } \\
\text { Improve (hari) }\end{array}$ & $\begin{array}{c}\text { Persentase } \\
\text { Pengurangan Waktu } \\
(\%)\end{array}$ & Implementasi Improve \\
\hline 1 & Desain & Kesalahan Desain & 82 & 50 & 39 & Daily Huddle Meeting \\
2 & $\begin{array}{c}\text { Pelaksanaan } \\
\text { Proyek }\end{array}$ & $\begin{array}{c}\text { Variation in } \\
\text { Quantities }\end{array}$ & 69 & 55 & 20 & Alliance \& Partnering \\
3 & $\begin{array}{c}\text { Pelaksanaan } \\
\text { Proyek }\end{array}$ & Tanah Longsor & 239 & 201 & 15 & Work Structuring \\
\hline
\end{tabular}

Sumber: Hasil Olahan 
Menurut Garnet teknik Alliance \& Partnering terdapat strategi untuk merespon kondisi pasar dan cara membuat keputusan dan mengidentifikasi proyek yang sesuai (potensial)[5]. Langkah ini mengatur supply chain untuk menyediakan produk dalam hal ini mesin, supplier terlibat dalam pengembangan produk dan implementasi proyek sejak awal. Mereka juga bertanggung jawab mengatur subsupplier, hubungan-hubungan didalam supply chain termasuk mengenai memonitor sesuai panduan, dimensi produk, kualitas mesin dan pengiriman. Terakhir, stakeholder bertanggung jawab untuk pengembangan di dalam supply chain, termasuk teknologi yang digunakan dan lain sebagainya.

Pada variabel kesalahan desain yang menggunakan Lean Construction yang menggunakan teknik Daily Huddle Meeting, menurut Iwan, menetapkan adanya pertemuan internal pada awal jam kerja secara rutin untuk setiap harinya berkisar antara 3-15 menit (berupa Stand Up Meeting) kemudian melakukan penyampaian informasi ataupun mengingatkan divisi lain di dalam meeting terkait hubungan antar aktivitas yang dikerjakan pada hari tersebut[6]. menurut DHS, langkah lain yang dapat dilakukan adalah melakukan evaluasi harian pada hasil yang tampak jelas. Kemudian untuk menciptakan komunikasi terbuka toolbox meeting (membahas metode baru, dll) untuk evaluasi dengan menggunakan Last Planner, dimana menurut Seppänen, dkk yakni dengan menganalisa kegagalan atau kurangnya pencapaian terhadap perencanaan sebelumnya (reason for failure analysis) dan melakukan koordinasi terhadap perencanaan yang baru kepada keseluruhan pekerja yang terlibat dalam aktivitas proyek [7]. Tools Last planner sendiri meliputi penambahan personal dalam tim, analisa terhadap ketersediaan sumber daya, penyusunan rencana mingguan, mengikutsertakan mandor untuk memberi masukan, evaluasi mingguan, koordinasi perencanaan baru, dan rapat harian rutin dan kontrol di lapangan.

Tanah longsor menggunakan Lean Construction dapat diaplikasikan di teknik Work Structuring, dimana menurut Abduh, dengan melakukan perencanaan terhadap metode pelaksanaan untuk pengerjaan proyek konstruksi kemudian membentuk sebuah tim yang khusus yang berperan untuk merencanakan desain mesin dan melakukan pemilihan sub supplier mesin yang memiliki tanggung jawab tinggi (biaya, mutu dan waktu) [8]. Sedangkan menurut Seppänen, dkk Work Structuring dapat dilakukan dengan membentuk tim khusus untuk merencanakan dan mengevaluasi metode pelaksanaan [7].

Dengan melakukan improve di tahap kesalahan desain mampu mengurangi keterlambatan sebesar $39 \%$, improve di tahap Variation in Quantities mampu mengurangi keterlambatan $20 \%$ dan improve di tahap Tanah Longsor mampu mengurangi keterlambatan sebesar 15\%. Secara keseluruhan dapat mengurangi waktu keterlambatan di proyek PT. Jatim Taman Steel dari 60 hari menjadi hanya sekitar 14 hari atau mampu meminimalisir keterlambatan sebesar 24,667\%. Dari penjelasan di atas dapat disimpulkan bahwa permasalahan yang perlu diperhatikan kedepan adalah bagaimana melakukan langkah pencegahan dan penanganan atau improve yang tepat jika keterlambatan pada proyek terjadi. Keterlibatan semua Stakeholder dalam menjalankan tugas masing-masing perlu untuk dipantau agar kesalahan desain, variantions in quantities dan rework dapat dihindari.

Pada penelitian lain oleh Saputra, hanya mengidentifikasi apakah perusahaan kontraktor di Indonesia sudah menggunakan konsep Lean Construction di dalam proyek yang pernah dikerjakan, tapi tidak meneliti secara detail langkah improve yang dapat diaplikasikan dalam sebuah proyek konstruksi untuk mengatasi keterlambatan dan mengurangi waste [9]. Dari penelitian tersebut terdapat pembuatan kategori tools yang dapat di aplikasikan dalam proyek konstruksi, dimana beberapa didalamnya digunakan untuk tahap improve penelitian yang dilakukan.

Penelitian oleh Randy, mempunyai tujuan memetakan kesalahan yang terjadi di PT. Kuda-Kuda Total tapi tidak memberikan improve apa yang harus diterapkan jika sudah memetakan kesalahan yang terjadi [10]. Namun di penelitian ini ada pengukuran pencapaian kualitas "level sigma" pada prosesnya, sehingga hasil dari "level sigma" akan sangat mudah untuk membandingkan dua atau lebih proses yang berbeda dan ingin mengetahui mana yang lebih baik kinerjanya.

\section{Simpulan}

Kesimpulan dari penelitian ini yaitu penyebab utama keterlambatan di Proyek PT. Jatim Taman Steel adalah Tanah Longsor, Variation In Quantities dan Variabel Kesalahan Desain. Quality Improvement yang dilakukan pada variabel Tanah Longsor menggunakan tools Daily Huddle Meeting yang diterapkan pada tahap pelaksanaan proyek, variabel Variation In Quantities menggunakan tools Work Structuring yang diterapkan pada tahap pra konstruksi dan untuk variabel Kesalahan Desain menggunakan tools alliance \& partnering yang diterapkan pada tahap pra konstruksi. Secara keseluruhan dapat mengurangi waktu keterlambatan di proyek PT. Jatim Taman Steel dari 60 hari menjadi hanya sekitar 36 hari atau mampu meminimalisir keterlambatan sebesar $24,667 \%$. 


\section{Daftar Pustaka}

[1] M. Sambasivan and Y. W. Soon, "Causes and effects of delays in Malaysian construction industry," Int. J. Proj. Manag., vol. 25, no. 5, pp. 517-526, Jul. 2007.

[2] L. Ernst \& Young, "2013 Transfer pricing global reference guide," 2013 Transf. pricing Glob. Ref. Guid., no. February, 2013.

[3] Y. unit. Messah, T. Widodo, and M. Adoe, "Kajian Penyebab Keterlambatan Pelaksanaan Proyek Konstruksi Gedung di Kota Kupang," J. Tek. Sipil, vol. II, no. 2, pp. 157-168, 2013.

[4] M. Abduh, Pengenalan Konstruksi Ramping”, Kerjasama ITB dan Direktorat Jenderal Bina Konstruksi. Kementrian PUPR, 2016.

[5] N. Garnett, D. T. Jones, and S. Murray, "Strategic Application of Lean Thinking," Proc. 8th Ann. Conf. Int'l. Gr. Lean Constr., no. October 2011, 1998.

[6] J. Iwan, "Studi Implementasi Sistem Last Planner Pada Proyek ' $x$ ' di Surabaya," Petra Christian University, 2009.

[7] O. Seppänen, G. Ballard, and S. Pesonen, The Combination of Last Planner System and LocationBased Management System, vol. 6. 2010.

[8] M. Abduh and H. A. Roza, "Indonesian Contractors' Readiness Towards Lean Construction," Underst. Manag. Constr. Process Theory Pract. - 14th Annu. Conf. Int. Gr. Lean Constr. IGLC-14, pp. 543-549, 2006.

[9] D. T. Saputra, "Lean Implementation to Improve Indonesian Construction: Incorporating Lean Principles to Improve Indonesian Construction by Minimising Rework Problems," Northumbria university, 2013.

[10] N. Randy, "Pengukuran Kualitas Berdasarkan Konsep Six Sigma Dalam Proyek Konstruksi (Studi Kasus pada PT. Kuda-Kuda Total Prima)," UAJY, Yogyakarta, 2005. 
